\title{
Taking a Life Course Perspective on Social Assistance Use in Canada: A DiFFERENT APPROACH ${ }^{1}$
}

\author{
Martin Cooke, PhD \\ Amber Gazso, PhD
}

\begin{abstract}
In this paper we argue that a life course perspective on social assistance use in Canada can offer a more nuanced theoretical understanding of both individuals' experiences and the importance of social structure, than more traditional sociological or economic approaches to welfare use. We also propose that examining social assistance use in this way does not require longitudinal quantitative or qualitative data, as is sometimes suggested, but that cross-sectional quantitative and qualitative data can be interpreted through a life course lens. We demonstrate this by examining the covariates of social assistance receipt using crosssectional quantitative data from the Survey of Labour and Income Dynamics, and by analyzing qualitative interviews with recipients about the process of beginning and barriers to ending benefit receipt. These analyses show not only how the cross-sectional data can easily be considered from the perspective of the life course, but also how this perspective provides a more satisfactory understanding of how social assistance policies can be thought of as both providing resources that are important in individual decision-making and as shaping lives.
\end{abstract}

Keywords : Social Assistance, Canada, lone mothers, welfare state

Résumé. Dans cet article, nous montrerons que le paradigme du parcours de vie sur le bien être social au Canada peut offrir une compréhension théorique plus nuancée des expériences des individus avec ces programmes qu'une approche traditionnelle sociologique et économique face à l'usage du bien être social, tout en reliant cet usage à de plus larges structures sociales. Nous proposons aussi qu'examiner l'assistance sociale de cette façon ne requiert pas de données longitudinales quantitatives ou qualitatives, tel qu'il l'est parfois suggéré, mais que des données quantitatives et qualitatives qui se croisent peuvent être interprétées

1. Acknowledgements: This research was supported by two Social Sciences and Humanities Research Council of Canada Doctoral Fellowships. The authors also gratefully acknowledge the women who voluntarily shared their experiences for this research. Disclaimer: The analysis used data from Statistics Canada. The results and views expressed here do not represent the views of Statistics Canada. 
à travers la loupe de la durée d'une vie. Nous démontrons ceci en examinant les covariantes de la réception à l'assistance sociale, covariantes agencées en se servant des données quantitatives sectionnelles tirées du Enquête sur la dynamique du travail et du revenu (EDTR) et en analysant les interviews qualitatives des bénéficiaires à propos de leurs démarches initiales et leurs obstacles jusqu'à la réception finale de leurs bénéfices. Ces analyses montrent non seulement que des données sectionnelles qui se croisent peuvent être facilement considérées du point de vue de la perspective du cours d'une vie, mais aussi comment cette perspective fournit une compréhension plus satisfaisante de la façon dont on peut voir la double importance des politiques qui offrent des ressources aux individus et qui changent leur vie.

Mots clés: le bien être social; Canada;

D rovincial social assistance programs, which are the bottom tier of state income support in Canada, have been the subject of dramatic restructuring since the early 1990s. Changes to these programs in several provinces (i.e., British Columbia, Alberta, Saskatchewan, and Ontario), particularly in light of the replacement of the Canada Assistance Plan with the Canada Health and Social Transfer in 1996, have included reductions in benefits, increasingly restrictive rules and eligibility requirements, and the growth of welfare-to-work programming. In Canada and other countries a neoliberal political discourse has contributed to a transformation in social assistance policies, from what were perceived as "passive" income support programs, providing benefits primarily on the basis of need, to more "active" policies which seek to reconnect individuals to the labour market as soon as possible.

The goal of these more active welfare programs is generally to promote "self-sufficiency" through paid work, rather than "dependence" of individuals and families upon welfare, thereby reducing state costs, deficits, and taxation in the context of international economic competition and open and globalized economies (Scharpf and Schmidt 2000). Individualism and "independence" have become key values and citizens of the contemporary neoliberal welfare state are presumed to be independent, self-sufficient, and flexible, and therefore willing to embrace personal and financial risks in the labour market and to personally manage the negative or positive outcomes (Brodie 1996). These changes are not at all unique to Canada, and similar welfare state restructuring can be seen in a number of other industrialized countries, including the other "liberal" Anglo-American welfare states of the United States (US), Great Britain, and Australia (Esping-Andersen 1999). In particular, Canadian changes have coincided with the US introduction of Temporary Aid for Needy Families (TANF) and its attendant benefit reductions and time 
limits under US President Clinton's Personal Responsibility and Work Reconciliation Act (PRWORA) (Bashevkin 2002).

Popular sociological perspectives on this welfare state restructuring emphasize how policy, the labour market, and social structures of class, race/ethnicity, and gender constrain individuals' economic choices and perpetuate their poverty. In contrast, economic and rational choice approaches have placed the primary responsibility for poverty on the employment, marriage, and childbearing decisions made by individuals. While both approaches have had considerable influence on policy debates (the latter more than the former), adopting one or the other encourages an inhibiting dichotomy that polarizes debates about restructuring and its effects on individuals and ignores the theoretically important tension between structure and agency. One way to incorporate both social structures and individual action and choice into an examination of social assistance in Canada is to adopt a life course perspective. ${ }^{2}$

In broad terms, life course research examines the patterns, timing, and experience of transitions within the interrelated domains of work and education, health, and family. The life course exists both in normative ideas of age-graded transitions and stages, as well as the observed trajectories taken by individuals. These trajectories are seen as affected by a number of factors including history, social structures of gender, age, race/ethnicity and class, relationships with others, as well as individual decisions (Marshall and Mueller 2003). The life course, as set of normative stages and also as observed trajectories, is shaped and reinforced partially by the assumptions and rules of state programs that reinforce gender, race/ethnicity, class, and age as dimensions of social inequality.

The life course can also be thought of in terms of resources. The transitions and trajectories experienced by individuals are connected to the stocks and flows of various interrelated types of "capital" possessed by individuals, including human, financial, health, social (Policy Research Initiative 2004). For example, a transition from welfare to work may increase a mother's human and financial capital but may also affect her health through increased demands for balancing paid work and caregiving (O'Campo and Rojas-Smith 1998). The life course reinforces the importance of timing of transitions and the idea that previous experiences form the context of later decisions. Because earlier transitions affect the resources available to meet later challenges, trajectories can become

2. While we recognize that the theoretical concept of agency is often underdeveloped in life course research (Marshall 2000) we do not attempt to correct for it here. Our interest is in how a life course framework can allow for the consideration of both how individuals actively shape their own lives as well as how their choices are structurally constrained. 
increasingly positive or negative over time, and the options available to individuals may become more plentiful, or increasingly constrained.

A life course perspective provides a framework for empirical analysis of social policies that incorporates important insights from both structural sociological and rational economic approaches. Thus far, it has largely been European researchers who have applied this framework to examine the role of state programs in shaping individual lives while recognizing the importance of individual intentionality and decisionmaking (Daly and Rake 2003; Leisering and Leibfried 1999). The perspective has gained influence in Canadian policy research partly because of the federal government's Policy Research Initiative's (PRI) recommendation of a life course framework to examine policy questions in the areas of health, retirement and pensions, and the labour market (Policy Research Initiative 2004). However, there have been few attempts to use such a framework to analyze particular policies in Canada.

In this paper, we argue that a life course perspective offers a stronger and more nuanced interpretation of individuals' experiences with social assistance than the more one-sided views offered by structural or rational choice approaches. First, we review traditional approaches to social assistance use in sociology and economics. We then explain how a life course perspective can be used to understand social assistance use in a way that corrects for some of the limitations of traditional approaches. In our third section, we discuss how this perspective can be used to interpret empirical cross-sectional data, a possibility that is growing in importance in contemporary applications of this perspective. We then offer our own application of this approach and consider the insights we gain from an integrated analysis of quantitative and qualitative data in our discussion. We conclude that a life course perspective illuminates the interconnections between factors that contribute to the use of social assistance, and inhibit choices to exit assistance, in ways that are superior to other approaches. ${ }^{3}$

\section{Traditional Approaches to Social Assistance Use}

Sociological treatments of the history of and recent changes to welfare in North America mainly address how these policies reinforce and reproduce structures of gender, race, and class. In Canada, a primary focus has been on the implications of these recent changes for women, who as

3. The data we draw upon are from two separate studies. Our intent is not to offer a mixed methodological study of the life course factors that lead mothers to claim or stay on assistance. Rather our intent is to use separate but compatible studies to support the arguments that we make in our paper. 
lone mothers constitute a large proportion of the total welfare caseload. Scholars such as Little (1998; 2001), writing from a feminist perspective, describe how social assistance programs continue to reproduce and reinforce the patriarchal nuclear family. Others illustrate the problematic implications of the recent changes for women, including what some see as the use of therapeutic interventions to encourage a work ethic (Brodie 1996), and how these programs often fail to provide any real training or educational opportunities while pressuring recipients to take any available work, regardless of whether it is likely lead to real "independence" (Evans 1992; McMullin, Davies, and Cassidy 2002). Still others, from a class perspective, show how these highly stigmatized programs discipline the low-wage workforce, ensuring that state provision does not compete with minimum wage work (Piven and Cloward 1993). A strong concern of analysts of social welfare in the US is the racialization of poverty, making race/ethnicity a key dimension in welfare discourse (Fraser and Gordon 1994; Gordon 2001).

In contrast, economic and econometric approaches to social assistance focus on understanding the work or welfare "choice" (e.g., Charette and Meng, 1994). Econometric analyses treat welfare receipt as the result of an individual's cost/benefit calculation, conditioned by human capital and earning potential in the extant labour market, as well as constraints on paid work such as the presence of children. These analyses show how individuals with greater earnings potential in the labour market are more likely to "choose" work over welfare if the benefits of work, measured by wage rates, exceed the benefits available from social assistance. The policy implications of this approach include some attempts to "make work pay" through earnings subsidies (Mijanovich and Long 1995) along with the aforementioned emphasis on reducing benefit levels and imposing time limits on benefit receipt in some cases.

Ultimately, neither the structural focus of sociology nor the rational choice focus of economics provides an adequate framework for understanding the role of social assistance in individual lives. "Dependency" on social assistance implies an absence of choice; structural approaches can overemphasize the degree to which social assistance receipt is determined by one's location in gender, class, or race/ethnic relations. Although lone mothers are more likely to receive benefits, women ultimately choose whether to receive benefits as part of complex strategies by which they seek to balance immediate caring and financial needs and to achieve various goals and execute plans for the future (Edin and Lein 1996). At the same time, emphasizing choice ignores the importance of location in social structures of inequality, including gender, race/ethnicity, age, and social class, for one's risk of poverty and social assistance 
receipt. Rational choice and human capital approaches are also blind to the role of state programs in reproducing various aspects of social structure. Neither approach adequately considers the ways in which the lives of individuals on social assistance are shaped by social structures as well as by their own decisions and strategies.

\section{Taking a Life Course Perspective on Social Assistance Use}

The life course perspective has grown out of a number of disciplinary concerns, including those of developmental psychology, the sociology of aging, and political science. Within sociology, the life course is a recent manifestation of the long-held sociological interest in age-linked social roles and the "life cycle." Most strongly promoted in its American form by the work of Glen H. Elder, Jr., the life course can be seen as a series of age-graded patterns embedded in various social institutions (O'Rand, 1996). As the work of Elder and others has shown, these age-graded patterns are subject to historical change, and demonstrate considerable variability between cohorts (e.g., Elder 1994). The life course therefore exists at both the aggregate level, as a set of normative expectations and cohort patterns, as well as at the individual level, as individual trajectories and transitions.

Empirically, life course researchers are often concerned with the prevalence, timing, and sequencing of particular life events such as marriage, childbirth, home-leaving, work, and retirement (Mayer and Tuma 1990). Several key influences affect the individual's experience and timing of transitions as they move through events or along "trajectories" in these various domains. These include human development and biological aging; social structures and institutions; historical time and place; the timing of previous experiences, connections, and relationships with others; and human agency and decision making (Marshall and Mueller 2003). Personal factors and interests are assumed to intersect with social structural factors and institutions as individuals progress through their life courses (Connidis 2001; Gunnarsson 2002; Morgan 1996). As previous events condition the experience of future ones, these trajectories can become increasingly beneficial, or more difficult, for individuals. Cumulative advantage or disadvantage, sometimes known as Merton's "Matthew effect" has become important in US life course studies. This research has examined the life-long consequences of out-of-sequence or out-of-timing events or disruptions to educational or work careers (O'Rand 1996). 
German life course research places a somewhat greater emphasis than US and Canadian research on the role of social institutions and welfare state policies in shaping the life course (Leisering 2003). Kohli (1986) points out the importance of social policies, principally education and retirement programs, in the creation of an expected sequence of life course transitions and the familiar "tripartite" life course of men, progressing through education, work, and retirement. While such universal programs create the broad outlines of the normative working life course, income replacement programs such as social assistance, employment insurance, and workers' compensation provide support for those whose life courses have deviated from the established norm (Leisering 2003). For example, the state provides social assistance support for lone mothers who have either made a transition to motherhood outside of a committed relationship, or whose relationships have ended.

At the same time as the welfare state provides support for those who have made such "out-of-sequence" transitions, it also attempts to structure their lives. The current emphasis on "active labour market policy" and welfare-to-work programs demonstrates how the programmatic features of these policies shape individual life courses by moving people back into the labour market. For example, in the four provinces of British Columbia (BC), Alberta, Saskatchewan, and Ontario, social assistance programs legally mandate "employable" recipients to engage in job searches, résumé classes, or education programs. As of 2002, BC is the only province in Canada to limit the amount of time employable recipients can access income support (for two out of every five years). When the province of Ontario introduced mandatory welfare-to-work programming in 1997 under Ontario Works, it was accompanied by a dramatic $21.6 \%$ reduction in benefit rates. In both provinces, reforms such as these were adopted to promote - or force - work effort. The stigmatizing and punitive effects of social assistance and low benefits therefore serve to discipline those who would otherwise opt out of paid work (Piven and Cloward 1993), and mothers who might opt out of a relationship (Mink 2001).

Of course, these policies are themselves fundamentally shaped by social structures, including gender, social class, race/ethnicity, and age. A life course perspective on social assistance use has the advantage of recognizing and incorporating these social structures of inequality, as well as individual agency, into a framework for analysis. From the structural perspective, social assistance programs may be thought of as part of the complex of policies and institutions that establish and reinforce gendered macrolevel life course patterns (Kohli 1986). As feminist researchers have shown, social assistance policy reflects changing ideological 
notions of gender relations. Canadian social assistance programs and the previous Mothers' Allowance have historically supported the patriarchal nuclear family and women's role as caregivers rather than breadwinners. The ideals of motherhood that have been reinforced through surveillance of lone mothers can be seen as classed as well as gendered, and represent an imposition of middle-class norms of family onto working-class women (Little 1998).

At present, the push toward welfare-to-work programs, even for lone mothers with young children, demonstrates that women are considered to have a "gender-neutral worker-citizen status" and are viewed more as potential wage earners than as caregivers and mothers (Breitkreuz 2005; Brodie 1996; O'Connor, Orloff, and Shaver 1999; Scott 1999). For example, since 1993, Alberta lone mothers are expected to seek work when their youngest children reach the age of six months. While lone mothers can act as caregivers until their youngest children are three years old in $\mathrm{BC}$ or attending full-time education in Ontario, Saskatchewan mothers can be expected to engage in welfare-to-work programming at any time at the discretion of their caseworkers (Schafer and Clemens 2002; Tweed 2004). Despite the absence of affordable, high-quality, and flexible day care, mothers' claims on the state for income support are understood to be the same as men's and they are expected to participate in employment programming in the same way as men (Evans, 1992; Scott, 1999). Nonetheless, even in their recent and current forms, assistance programs can reinforce women's economic dependence on men through regulations such as the "spouse-in-the-house" rule in Ontario (now terminated) with the expectation that if there is a man in the household, he should be considered the "breadwinner"(Little and Morrison 1999).

Assumptions surrounding race/ethnicity infiltrate social assistance policy and discourse as well. Fraser and Gordon (1994) describe how the discourse of "welfare dependency" in the US is fundamentally racialized, as well as gendered, with stereotypes such as the Black "welfare queen" appearing regularly in popular media. In Canada, the discourse has perhaps been less racialized, but there are examples of welfare programs being explicitly shaped by ethnicity. In the earlier Mothers' Allowance programs, benefits were often unavailable to immigrant or Aboriginal women, either because of explicit rules or because they lacked supporting documents such as birth certificates (Little 1998). Immigrant status continues to be a factor in social assistance receipt, as immigrants may be restricted from claiming benefits for a time through various sponsorship arrangements. Aboriginal peoples are more likely than other Canadians to be reliant on social assistance and other transfer payments. Moreover, people who are registered under the Indian Act and living in 
reserve communities are served by federal programs rather than provincial ones, with different rules and regulations (Indian and Northern Affairs Canada 2003).

Welfare state programs can be thought of as age-graded, with programs serving people at different times of life. Although the general trend of neoliberal restructuring has transformed eligibility, notions of entitlement and benefit amounts of core welfare programs, existing child tax benefits, education and student loans, employment insurance, old age security, and pension and retirement policies all mark out individuals or families in specific stages of their life courses as their primary clientele. In the case of social assistance, lone mothers with young children remain a key group (National Council on Welfare 1997). In general, welfare tends to provide support for those in early adulthood, but there is a small proportion of recipients who are in the position of receiving income support in early mid-life, between age 40 and 55; social assistance policy, however, is not always adequately prepared for managing the unsteady employment experiences of low-income individuals in mid-life (Gunnarsson 2002).

At the same time as it allows for an understanding of the ways that social assistance and other welfare state programs structure the life course at the aggregate level, the life course perspective demands that individual choice regarding benefit receipt be recognized. Social assistance is an important resource individuals choose to use as a means to respond to situations in their own lives. As Leisering and Leibfried (1999) found in their study of social welfare use in Germany, the decision to take up benefits often supports particular goals, such as ending an unsuitable relationship and establishing a new household, or having and raising children. In their qualitative study of lone mothers in the US, Edin and Lein (1996) demonstrate the role of social assistance as a resource, chosen by women as part of their strategies for providing materially and emotionally for their children. Indeed, econometric studies of both the probability of receiving social assistance, and the duration of social assistance receipt, confirm that lone mothers are more likely to receive social assistance and tend to choose to do so for longer when benefit rates are higher and the expected wage rate or the likelihood of finding a job are lower (Charette and Meng 1994; Stewart and Dooley 1999). These economic models acknowledge "choice" in welfare receipt, but generally ignore the importance of location in structures of gender, class, and race/ethnicity for the risk of poverty and social assistance receipt, as well as the role of social assistance programs in reinforcing these structures of inequality and constraining choices through punitive and stigmatizing regulations. 
The life course, as we have described above, is not a singular theory but an analytical perspective that can incorporate insights from various theoretical approaches. These include critical and structural perspectives on the role of state programs in reproducing gender, class, race/ethnicity, or age relations, and provide a framework by which these effects can be examined at either the aggregate or individual level. At the same time, the perspective emphasizes how, at the individual level, the life course is actively constructed through actions and decisions that are taken in the context of past events as well as various structural and institutional constraints. Rather than discounting entirely the emphasis on "choice" that is found in the economic models of social assistance, a life course perspective places these choices in their proper social-historical and structural contexts, as well as focusing attention on the goals which motivates them. Lastly, its attention to multiple domains, including work, the family, and health, allows research to span a wide variety of disciplinary interests, including the types of events and life course patterns that lead to social assistance, as well as the implications of social assistance receipt for the later life course.

\section{IMPLiCATIONS For the INTERPRETATION OF Cross-SeCtional EMPIRICAL RESEARCH}

Quantitative and qualitative longitudinal methodologies have been used fruitfully to examine both the characteristics of life courses on the aggregate level, as well as individual trajectories and the meanings associated with various events or transitions for individuals (Giele and Elder 1998). One of the strengths of the life course perspective is its dynamic approach, resulting from an interest in timing and sequence and the implications of previous events for the experience of later events. This coincides with an increased availability of longitudinal survey data in recent years, along with techniques to analyze them. However, to maintain that using a life course perspective demands longitudinal data research is unnecessarily restrictive.

Although the "dynamic" approach of life course studies is generally taken to mean the use of longitudinal data, other scholarly research informs us that purely prospective longitudinal studies are not absolutely required for an application of a life course framework. Scott and Alwin (1998) argue that both prospective and retrospective quantitative and qualitative research designs are valuable for life course researchers, although each has associated advantages and disadvantages from the perspective of recall, reliability, completeness, and sensitivity to 
short-term changes. They explain that interpretation of cross-sectional quantitative data collected for a life course study requires little deviation from traditional approaches to longitudinal data. A current state is seen as the culmination of experience, with the main difference being that the pathways to that experience are left unobserved (Scott and Alwin 1998). Regarding qualitative interview data, there are various strategies for collecting retrospective narrative accounts of the life course or conducting "life course interviews," including life history "grids" and calendars in cross-sectional studies (Parry, Thomson, and Fowkes 1999; Scott and Alwin 1998).

We differ from other scholars in the use of the life course perspective as a general framework for analysis and interpretation that is, in some ways, independent of the collection of data. We contend that even data collected without the life course perspective explicitly in mind can be analyzed to answer questions derived from such a perspective, and that the results of many seemingly "static" cross-sectional retrospective quantitative and qualitative studies can be interpreted in a way sensitive to its dynamic approach. Considering an application to quantitative data, variables such as educational attainment, occupation, marital status, current income, and any number of "static" characteristics are, from the perspective of the life course, an outcome of previous life course events and trajectories that may or may not also be captured in the survey. Even qualitative data that are not collected using the technique of the "life course interview" are often used to investigate research questions surrounding the meanings and intentions ascribed to various experiences and transitions, and the context of decision making - issues that are easily incorporated into a life course perspective. Applied to qualitative data, a life course perspective allows one to perceive and interpret the meanings and reasons behind peoples' experiences in light of past events, sociohistorical context, and structural conditions. This means assuming individuals' active shaping of their own lives through their own decision making, as well as understanding the situations to which they are responding.

A life course perspective therefore permits us to view receipt of social assistance as a specific time-limited event within a dynamic individual life course. This is fitting given the evidence of the temporary but often repeated nature of social assistance receipt over a period of time (e.g., Stewart and Dooley 1999). As with poverty, social assistance receipt may or may not be a long-term state, although the duration of assistance receipt and the possibility of multiple spells are clearly important aspects of the life course (Leisering and Leibfried 1999) 
In the following section we provide a descriptive account of findings on mothers' use of social assistance from two studies. In the concluding section, we integrate findings from these studies in order to substantiate our argument that a life course perspective can be theoretically illuminating when applied to cross-sectional data.

\section{Social Assistance and the Life Course: Evidence from the Survey of Labour and Income Dynamics}

One of the few Canadian sources of data on social assistance receipt, which also includes information on family status, education, and other aspects of individuals' life courses, is the Survey of Labour and Income Dynamics (SLID). The SLID is a survey of roughly 30,000 individuals in 16,000 households, conducted in six-year overlapping panels that can be used longitudinally or as separate cross-sectional samples (Statistics Canada 1994). Using these data, we are able to address questions related to the life course and particularly the aspects of the life course that affect the probability of social assistance receipt for lone mothers. ${ }^{4}$

Not all aspects of the life course can be captured in a survey, but the SLID provides specific information on the domains of work, education, and the family. For example, a woman's marital history, especially whether she was ever married, might affect her likelihood of needing social assistance as a lone mother. Women who were married might be more likely to receive benefits from their former partners after the dissolution of a relationship than those who had lived in common-law partnerships, or had children outside of committed relationships. Following the life course principle that the timing of earlier transitions can be important to later events we also include the independent effects of age at certain events such as marriage, cohabitation, or her first birth, to ask whether women who have children earlier are more at risk for social assistance receipt. Educational attainment is measured by highest level of schooling, and reflects the endpoint of an educational career. Here, educational attainment of respondents' fathers is also included as a rough proxy for the social class of family of birth in order to take into account some aspect of intergenerational transmission of social status. Provincial dummies roughly capture the differences among provincial social assistance programs as well as some aspects of the local labour

4. Although the SLID is a longitudinal survey, its 6-year length is limiting for studies of relatively rare situations such as social assistance use. Unlike long-term prospective panels such as the US Panel Study on Income Dynamics (PSID), the SLID does not allow identification of first-time social assistance spells or examination of the longterm consequences of social assistance use. In these models, we make use of the crosssectional variables and weights. These data were accessed through the Statistics Canada South-Western Ontario Research Data Centre (SWORDC). 
markets, reflecting both the external constraints on finding paid work and the relative benefit rates. From a life course perspective, these factors are assumed to affect decisions about social assistance use. Disability status is considered a control variable in these models, as disability benefit programs and social assistance may be related and confused in reporting. However, current disability status could equally be considered to reflect an individual's position on a "health trajectory," another life course domain. ${ }^{5}$

Table 1 presents a logistic regression model predicting the probability that a lone mother, defined here as the female head of a census family who is between 18 and 59, reported receiving social assistance in any month in 2001, conditional on a number of variables and other covariates. Similar models were produced for all heads of census families, not limited to lone mothers, although the results are not presented here. A description of the SLID sample is provided in the Appendix.

As shown in Table 1, a lone mother who was ever married had a much lower likelihood of receiving social assistance in 2001, controlling for the other variables. Women who were single and never married, which would include those who had their children outside of the context of a marriage or common-law union, were more than three times as likely to have received social assistance in 2001. Although there were no significant independent effects of age, the age at which a woman had her first child had a slightly positive effect, just significant at the .05 level.

Women with university degrees, college, or technical diplomas were significantly less likely to receive social assistance in 2001, as were women with more years of full-time equivalent work experience. However, there were no independently significant effects for the education of a woman's father. The significantly negative effects of living with other adults indicates the lower chances of social assistance use among lone mothers who lived with others, such as their parents or other family members. Lone mothers in Ontario were the least likely to receive social assistance in 2001, while those in Alberta and Manitoba had odds that were more than four times those for Ontario lone mothers, and lone mothers in $\mathrm{BC}$ were five times as likely.

From the life course perspective, these data provide some important, if incomplete, information on the life courses of those lone mothers who were more at risk for social assistance use in 2001. As previous economic research has found (Charette and Meng 1994), having low education and a lack of previous work experience made it more likely that a lone moth-

5. Although immigrant status, visible minority status, or Aboriginal identity may also be important predictors of social assistance receipt, the SLID data did not include enough of these cases for an analysis. 
Table 1: Logistic Regression Models of Social Assistance Receipt by Female Lone Parents, 2001.

\begin{tabular}{|c|c|c|c|c|}
\hline & \multicolumn{4}{|c|}{2001} \\
\hline & Coeff & $\operatorname{Exp}(B)$ & S.E & $\operatorname{Pr}>X^{2}$ \\
\hline Intercept & -4.218 & & 1.068 & $<.0001$ \\
\hline \multicolumn{5}{|c|}{ Marital Status (Divorced or widowed $=r e f)$} \\
\hline Separated & 0.913 & 2.493 & 0.366 & 0.013 \\
\hline Single, never married & 1.131 & 3.098 & 0.392 & 0.004 \\
\hline Age & 0.048 & 1.049 & 0.026 & 0.069 \\
\hline Age at 1 st Birth & 0.071 & 1.073 & 0.036 & 0.050 \\
\hline \multicolumn{5}{|l|}{ Education (High School=ref) } \\
\hline Less than High School & 0.408 & 1.503 & 0.402 & 0.310 \\
\hline Degree or Certificate & -0.754 & 0.470 & 0.304 & 0.013 \\
\hline Years Work Experience & -0.228 & 0.796 & 0.028 & $<.0001$ \\
\hline \multicolumn{5}{|c|}{ Number of Preschool Children (none $=$ ref) } \\
\hline One & 0.033 & 1.034 & 0.423 & 0.937 \\
\hline Two & 0.488 & 1.629 & 0.590 & 0.408 \\
\hline \multicolumn{5}{|l|}{ Father's Education (High School=ref) } \\
\hline Less than High School & 0.391 & 1.478 & 0.344 & 0.256 \\
\hline Degree or Certificate & 0.001 & 1.001 & 0.560 & 0.998 \\
\hline Don't know & 0.351 & 1.420 & 0.496 & 0.479 \\
\hline Disability Status (No=ref) & 1.320 & 3.743 & 0.320 & $<.0001$ \\
\hline Lives with other Adults & -1.232 & 0.292 & 0.435 & 0.005 \\
\hline \multicolumn{5}{|l|}{ Provinces (Ontario $=$ ref $)$} \\
\hline Newfoundland/PEI/Nova Scotia & 0.772 & 2.164 & 0.797 & 0.332 \\
\hline New Brunswick & 1.199 & 3.318 & 0.473 & 0.011 \\
\hline Quebec & 0.413 & 1.512 & 0.370 & 0.264 \\
\hline Manitoba & 1.414 & 4.114 & 0.688 & 0.040 \\
\hline Saskatchewan & 0.883 & 2.419 & 0.684 & 0.197 \\
\hline Alberta & 1.441 & 4.224 & 0.542 & 0.008 \\
\hline British Columbia & 1.617 & 5.037 & 0.437 & 0.000 \\
\hline$N$ & 598 & & & \\
\hline$-2 L L$ & 391.178 & & & \\
\hline
\end{tabular}

er would receive social assistance. In the family domain, women who never married were more than three times more likely to receive social assistance than those who had married, but were divorced or widowed at the time of the survey (Table 1). Although the cross-sectional data do not provide details of these women's marital histories, the results do suggest that women who become lone mothers after the dissolution of a marriage may have access to more resources than those who whose marriages had ended after children were born. Similarly, although having a father with less than high school education was characteristic of social assistance receipt among major income earners generally (model not shown), it was not among lone mothers. Although by no means definitive, the social class of a woman's birth family might not be particularly important for 
the risk of social assistance after lone motherhood, independent of her own education, work, and marital history.

\section{Entering and Leaving Social Assistance: Evidence from Qualitative Interview Data}

The qualitative data in this paper are from interviews with 28 lone mothers on assistance in the three provinces of $\mathrm{BC}$, Alberta, and Saskatchewan, collected in the spring and summer of 2004. ${ }^{6}$ The majority of mothers interviewed had two children living with them at the time of the interviews. Six of the mothers interviewed had other children that were placed in outside care (e.g., foster care) or living with other family members. Across the provinces, the average age of all mothers ranged from 29-33. Most mothers had been on assistance for one or more years and reported low education levels (e.g., having some high school or a high school diploma) at the time of the interview. Twenty-two of the mothers were white whereas six reported Aboriginal or Métis identity. Although the majority of all mothers were on temporary or basic social assistance, only fifteen of the mothers interviewed were "expected to work," according to the provincial policies and were therefore involved in various welfare-to-work (e.g., education and training) programs. The remaining mothers were exempt from seeking work due to the age of their youngest children, because they had recently left an abusive relationship, or for medical or mental and physical health reasons. Although all lone mothers had cycled on and off of assistance, a finding supported by other research, all had been on assistance for one year or more at the time of the interview.

Mothers' use of social assistance was distinctly linked to their lone parent status, attributed to bearing a child outside of a union or their exit from a union. Tanya explains that her use of social assistance for the last five years was a direct result of her partner leaving her, and implies that the life course transition her family was about to experience - having a child - was actually partially responsible for her partner's leaving.

Tanya: I was working and then I got pregnant and then everything went "poof."

Interviewer: What do you mean when you say everything went "poof"?

Tanya: Well, my husband and I fought and everything, and we ended up separating and having a big fight. And, uh, then he left

6. The interviews discussed in this paper are derived from a larger comparative study on social assistance reform in BC, Alberta, and Saskatchewan, over the period 1993-2004 (see also Gazso 2006; 2007a; 2007b). In this research, mothers and fathers were approached for interviews through a process of purposive sampling at a central food bank in a major city in each province. Anonymity and confidentiality of interviewees is protected in this paper by the use of pseudonyms. 
and took off. And then I had my kid and he showed up for the birth and was there for a week and then he was gone.

Tanya, 26 year old lone mother of 4 year old son (SK)

In total, six mothers came to be on assistance after fleeing abusive relationships. In these mothers' experiences, abusive relationships had an impact on their identities and self-esteem. The transition from an abusive relationship to social assistance use as a lone mother was therefore a significant event in their lives. The following excerpt from Tamara, a 31 year old lone Aboriginal mother of five, illustrates these dynamics.

And that's when I was with my ex ... we were on there [welfare]... I didn't know the system. I didn't know how to ask for this and that ... I was very, um, sequestered and sheltered in this abusive relationship.... And being a single parent, holy smokes, that first year I had to learn how to get a house. I had to learn how to, um, talk to people cause that was very frightening ... I really, I'll say, woke up from a deep sleep.

Tamara, 31 year old lone mother of 5 children (SK)

Although employment events (e.g., dismissal from a job) less often led directly to social assistance than did health crises or marital disruptions, the sporadic employment histories of the mothers were important to their life histories and use of social assistance. For some mothers, it was the difficulty of juggling work and caring that led to their decisions to apply for assistance. In Lisa's case, previous events had removed two children from her care. Once she regained custody of two children from her ex-partner, her total of four children made it difficult to balance paid work at a local cedar mill and care as a lone mother.

Yeah, um, when I, the first time I worked at the cedar mill, um, I just had Diana and Grace. And my ex-husband had taken the other two. And so it took me like a year and a half to find them before they came back. And then, having the four kids, it was really difficult to find a babysitter. So I had to quit that job. So that's really the first time I went on assistance.

Lisa, 35 year old lone mother of 4 children $(B C)$

Recall that a life course perspective applied to reforms to social assistance policy highlights how restrictive welfare-to-work programming and enforcement of mothers' employability efforts are one way in which these policies shape women's life courses. In addition, recall that the perspective requires assuming and recognizing individuals' choices in light of their sociohistorical and structural context. Mothers retold how specific events and transitions led to their use of social assistance and how their previous trajectories made leaving welfare difficult. Despite policy efforts to move these women off welfare and into work, poor health, inadequate monthly benefit levels, and caregiving responsibilities all acted 
as barriers to their exit. Health conditions especially prevented mothers from seeking paid employment and exiting assistance. Moreover, the reform strategy of reducing benefit amounts meant that many mothers who were expected to attend programs to improve their human capital had difficulty attending because of a lack of transportation or childcare. Upon her initial application for assistance, Amy was expected to finish her Grade 12 education. While such a policy expectation would correct for her education deficits, it did not stack up fairly against her lack of income to afford the necessary transportation to attend the program. Not surprisingly, Amy's eventual choice was to drop out of the program as a result of these barriers.

And welfare was making me take this course but they didn't understand that I had to walk to it every morning. So you know, just for me to get there and then like I'd show up late and then by the time I'd get there it's time to turn around and go home. You know. I wasn't too enthusiastic with it.

Amy, 21 year old lone mother, 5 month old son (BC)

Other mothers who did attend employment-oriented programs questioned the extent to which programs on résumé building corrected for their skills deficiencies, which were most often due to their previous careers as home-based caregivers rather than paid workers. Moreover, caregiving responsibilities, including the management of their children's development and transitions (or life courses) inhibited some mothers' choices to change their own life courses through paid work participation. For some mothers, their main concern in considering their eventual entrance into paid work was the availability of hours of work, and recognition that many available jobs would not be compatible with caregiving.

She's gotta be able to start taking care of herself a little bit more before I can go out and do anything. Because a lot of jobs, well, they want you at their disposal all the time.... I know when you start at new places, you're bound by, oh, a couple weekends here and there and a few nights.

Candace, 36 year old lone mother, 6 year old daughter $(A B)$

Indeed, the majority of mothers considered the programs' expectations that they would participate in education, look for work, and eventually exit from assistance to be reasonable, providing that quality child care was available. Jessica, a 31 year old lone mother of three from Saskatchewan explained that while her two children over age six can attend school all day, she will have more difficulty with the type of care she can find for her youngest child once she engages in paid work:

There's a long, long waiting list to get him into any day care. I have to put him in a friend's house.... But quite frankly, it's better for him to be 
in an organized day care rather than just at somebody's house watching TV all day.

Jessica, 31 year old lone mother of two children

These mothers' responses to the perceived barriers inhibiting their exit from assistance highlight how their life courses are also the products of choices, albeit choices strongly shaped by gender structures. Some lone mothers "chose" to stay on assistance for as long as possible when their children were very young, or until their children reached an age at which their employability was fully enforced. Many invoked a mothering discourse to justify their right to assistance and to refuse to search for employment any sooner than what was required by policy.

For other mothers, it is far more difficult to argue that social assistance use was a deliberate choice once their distinct life courses are taken into consideration. Aside from life course dynamics in adulthood, including employment, marital dynamics, and education, socialization in childhood and young adulthood, as well as their experiences in their communities matter to their experiences on social assistance. Some mothers' use of social assistance as part of their life course trajectories was distinctly linked to their lack of interactions with others who supported specific life course events, such as completing a high school education. Theresa, a lone Aboriginal mother of six children, age 30, explains her own current situation by looking back over time in this way.

I think if, if I ... like I had people, people there at the time [to say] "go to school, go to school and get your grade 12 and get a job." Like, I probably had that said to me but I, it's just like, like what is there? But now, today you think of it, and I would say that I, I wish I was there now... like it's hard to get back to, especially if you don't know what's happened to you in ten years. You can have so much kids, you can have one, two kids, it's hard to get back.

Theresa, 30 year old lone mother of 6 children (SK)

In fact, it was Aboriginal mothers themselves who tended to link their use of social assistance to cultural assimilation through larger historical and colonial processes and their subsequent loss of traditional cultural values and ways of life.

To summarize, the qualitative findings demonstrate how these women came to be on social assistance as a result of becoming lone mothers, either after having children outside of a union or after leaving an abusive partner, or often after the onset of mental and physical health problems. The findings illustrate how these women's use of social assistance as well as their ability and decisions to exit welfare are shaped by previous events in interrelated life course domains. Finally, the findings also show 
how the resources that these women have accumulated through their life courses (e.g., health conditions, emotional and physical supports, human capital, financial resources) affect their choices about social assistance.

\section{Conclusions: Social Assistance Use from a Life Course Perspective}

In this paper we have used cross-sectional quantitative data and qualitative interview data in order to illustrate the utility of taking a life course perspective on social assistance use. Methodologically, we hope that we have demonstrated how this cross-sectional data - not collected explicitly from the life course perspective - can nonetheless be interpreted by using the principles and assumptions of this perspective Although longitudinal survey data or life course interviews are certainly useful and desirable, most of the extant data are not collected in this way. However, by viewing current states as the cumulative result of previous transitions, making use of the retrospective questions found in many large surveys, and by interpreting interview data with life-course principles in mind, these data can shed light on life-course questions.

The main advantage of the life course perspective, in our view, is that it provides the theoretical space for understanding social assistance use as a structured choice, made in the context of previous experiences and resources, which are themselves shaped by gender, class, age, and race/ ethnicity. Women's ongoing responsibility for childrearing makes it far more likely that they will be lone parents than will men, and therefore more likely to need social assistance. The quantitative model we present above provides evidence that women's education and previous labour force experience are protective, making social assistance less likely when women become lone mothers. However, the results also suggest that women who leave paid work for childcare may be at increased risk for reliance on social assistance, should they become lone mothers. The independent effect of marital history suggests the importance of social assistance as a resource for women who do not have former spouses for support.

The qualitative data are able to enrich our understanding of the ways in which women choose to begin or to stop receiving welfare in the context of their own education and work, health, and family trajectories, and interrelationships with the lives of others such as family members and former spouses. While these women's own narratives reflect varying degrees of self-confidence and feelings of efficacy and capacity, it is clear that they make these decisions in order to achieve certain goals 
and by taking account of their resources, among which social assistance must be counted.

From a policy perspective, the life course perspective also sheds light on recent changes to social assistance, especially in BC, Alberta, Saskatchewan, and Ontario. The reforms to welfare policy in Canada have generally taken the approach of either forcing recipients to participate in work or education activities or decreasing the amount of benefits in order to move people from welfare to work, under the assumption that people make a choice between welfare and work based primarily on the economic benefits expected from each. Although this is no doubt true to some degree, our conceptual perspective allows us to consider how the previous life courses of these women affect the resources they have available, as well as their ability to leave social assistance and to meet the newer restrictive requirements of social assistance programs. Applied to our data, we find the life course perspective to be particularly illuminative of the interconnections among factors that contribute to one's usage of social assistance and which may inhibit exits from social assistance. Our findings reinforce the importance of considering the interrelationships among the life course domains of marriage and family, health, and work and education for low-income lone mothers. These findings also support the feminist critiques of the changes to social assistance as disproportionately affecting women by not taking lone mothers' responsibilities for child care into account as they simultaneously reinforce their roles as workers. Indeed, from the perspective of the life course, one of the ways in which mothers' lives are structured by gender, class, age, and other dimensions of inequality, is through the assumptions and parameters of welfare state programs.

\section{REFERENCES}

Bashevkin, Sylvia 2002. Welfare Hot Buttons: Women, Work, and Social Policy Reform. Toronto: University of Toronto Press.

Breitkreuz, Rhonda. 2005. Engendering citizenship? A critical-feminist analysis of Canadian welfare-to-work policies and the employment experiences of lone mothers. Journal of Sociology and Social Welfare 32(2):147-165.

Brodie, Janine. 1996. Restructuring and the new citizenship. Pp. 126-140 in Isabella C. Bakker, ed., Rethinking Restructuring. Toronto: University of Toronto Press.

Charette, Michael and Ronald Meng. 1994. The determinants of welfare participation of female heads of household in Canada. Canadian Journal of Economics 27(2):290-306.

Connidis, Ingrid Arnet. 2001. Family Ties and Aging. Thousand Oaks, CA: Sage Publications. 
Daly, Mary and Katherine Rake. 2003. Gender and the Welfare State. Cambridge: Polity Press.

Edin, Kathryn and Laura Lein. 1996. Work, welfare, and single mothers' economic survival strategies. American Sociological Review 61:253-266.

Elder, Glen H., Jr. 1994. Time, human agency, and social change: Perspectives on the life course. Social Psychological Quarterly 57(1):4-15.

Esping-Andersen, Gøsta. 1999. Social Foundations of Postindustrial Economies. Oxford: Oxford University Press.

Evans, Patricia. 1992. Targeting single mothers for employment: Comparisons from the United States, Britain, and Canada. Social Service Review: 378398.

Fraser, Nancy and Linda. Gordon. 1994. 'Dependency' demystified: Inscriptions of power in a keyword of the welfare state. Dependency"' Demystified: Inscriptions of Power in a Keyword of the Welfare State 1, no. 1: 4-31.

Gazso, Amber. 2006. Gendering the responsible risk taker: Social assistance reform and parents' citizenship, market and family care relations in three western provinces. PhD Dissertation. Department of Sociology, University of Alberta, Edmonton, AB.

2007a. Balancing expectations for employability and family responsibilities while on social assistance: Low income mothers' experiences in three Canadian provinces. Family Relations 56:454-466.

2007b. Staying afloat on social assistance: Parents' strategies of balancing work and family. Socialist Studies 3(2):31-63.

Giele, Janet Z. and Glen H. Elder, Jr., eds. 1998. Methods of Life Course Research: Qualitative and Quantitative Approaches. Thousand Oaks, CA: Sage.

Gordon, Linda, ed. 2001. Who Deserves Help? Who must Provide? Edited by R. and Withorn Albelda, A. Special edition of the annals of the American Academy of Political and Social Science, 577.

Gunnarsson, Evy. 2002. The vulnerable life course: Poverty and social assistance among middle-aged and older women. Ageing \& Society 22:709-728.

Indian and Northern Affairs Canada. 2003. Basic Departmental Data 2003. Ottawa: First Nations and Northern Statistics Section, Corporate Information Management Directorate, Information Management Branch.

Kohli, Martin. 1986. The world we forgot: A historical review of the life course. Pp. 271-303 in Victor W. Marshall, ed., Later Life: The Social Psychology of Ageing. Beverly Hills, London, New Delhi: Sage.

Leisering, Lutz. 2003. Government and the life course. Pp. 205-229 in Jeylan T. Mortimer and Michael J. Shanahan, eds., Handbook of the Life Course. New York: Springer.

Leisering, Lutz and Stephan Leibfried. 1999. Time and Poverty in Western Welfare States: United Germany in Perspective. Cambridge: Cambridge University Press. 
Little, Margaret J.H. 1998. 'No Car, no Radio, no Liquor Permit': The Moral Regulation of Single Mothers in Ontario. Toronto: Oxford University Press.

2001. A litmus test for democracy: The impact of Ontario welfare changes on single mothers. Journal of Canadian Studies 34(2):110-136.

Little, Margaret and Ian Morrison. 1999. The pecker detectors are back: Changes to the spousal definition in Ontario welfare policy. Journal of Canadian Studies 34(2):110-136.

Marshall, Victor W. 2000. Agency, structure, and the life course in the era of reflexive modernization. In Symposium on "The Life Course in the 21st Century,” American Sociological Association meetings. Washington DC.

Marshall, Victor W. and Margaret M. Mueller. 2003. Theoretical roots of the lifecourse perspective. Pp. 3-32 in Walter R. Heinz and Victor W. Marshall, eds., Social Dynamics of the Life Course: Transitions, Institutions, and Interrelations. New York: Aldine de Gruyter.

Mayer, Karl Ulrich and Nancy Brandon Tuma. 1990. Course research and event history analysis: An overview. Pp. 3-15 in K.U. Mayer and N.B. Tuma, eds., Event History Analysis in Life Course Research. Madison: University of Wisconsin Press.

McMullin, Julie Ann, Lorraine Davies, and Gale Cassidy. 2002. Welfare reform in Ontario: Tough times in mothers' lives. Canadian Public Policy 28(2):297-314.

Mijanovich, Tod and David Long. 1995. Creating an Alternative to Welfare: First-year Findings on the Implementation, Welfare Impacts, and Costs of the Self-sufficiency Project. Ottawa: Applied Research Branch, Strategic Policy, Human Resources Development Canada.

Mink, Gwendolyn. 2001. Violating women: Rights abuses in the welfare police state. Special Edition of the Annals of the American Academy of Political and Social Science 577:79-93.

Morgan, David H.J. 1996. Family Connections: An Introduction to Family Studies. Cambridge: Polity Press.

National Council on Welfare. 1997. Another Look at Welfare Reform: A Report by the National Council on Welfare. Ottawa: Minister of Public Works and Government Services Canada.

O'Campo, P. and L. Rojas-Smith. 1998. Welfare reform and women's health: Review of the literature and implications for state policy. Journal of Public Health Policy 19(4):420-46.

O'Connor, Julia S., Ann Shola Orloff, and Sheila Shaver. 1999. States, Markets, Families: Gender, Liberalism and Social Policy in Australia, Canada, Great Britain and the United States. Cambridge: Cambridge University Press.

O'Rand, Angela M. 1996. The cumulative stratification of the life course. Pp. 188-207 in R.H. Binstock and L.K. George, eds., Handbook of Aging and the Life Course. New York: Academic Press. 
Parry, Odette, Carolyn Thomson, and Gerry Fowkes. 1999. Life course data collection: Qualitative interviewing using the life grid. Sociological Research Online 4(2).

Piven, Frances Fox and Richard Cloward. 1993. Regulating the Poor: The Functions of Public Welfare. Updated edition. New York: Vintage Books.

Policy Research Initiative. 2004. A Life-course Approach to Social Policy Analysis: A Proposed Framework. Ottawa: Policy Research Initiative.

Schafer, Chris and Jason Clemens. 2002. Public Policy Sources, Welfare in Saskatchewan: A Critical Evaluation. Vancouver: The Fraser Institute Occasional Paper.

Scharpf, Fritz W. and Vivien A. Schmidt. 2000. Introduction. Pp. 1-20 in Fritz W. Scharpf and Vivien A. Schmidt, eds., Welfare and Work in the Open Economy: From Vulnerability to Competitiveness. Toronto: Oxford.

Scott, Jacqueline and Duane Alwin. 1998. Retrospective versus prospective measurement of life histories in longitudinal research. Pp. 98-127 in Janet Z. Giele and Glen H. Elder, Jr., eds., Methods of Life Course Research. Thousand Oaks, CA: Sage.

Scott, Katherine. 1999. The dilemma of liberal citizenship: Women and social assistance reform in the 1990s. Pp. 205-235 in Pat Armstrong and M. Patricia Connelly, eds., Feminism, Political Economy and the State: Contested Terrain. Toronto: Canadian Scholars' Press.

Statistics Canada. 1994. Survey of Labour and Income Dynamics User's Guide Wave 2, 1994. (Cat no 75M0001GPE). Ottawa: Ministry of Industry.

Stewart, Jennifer and Martin D. Dooley. 1999. The duration of spells on welfare and off welfare among lone mothers in Ontario. Canadian Public Policy 25(Supplement 1):s47-s72.

Tweed, Gord. 2004. Personal communication with associate executive director, operations and delivery support, employment and income assistance. Regina.

Martin Cooke is Assistant Professor at the University of Waterloo, where he is jointly appointed to the departments of Sociology and Health Studies and Gerontology. His main area of research is the relationships between age, gender, race/ ethnicity/indigeneity and social policy. He is currently the principal investigator of a SSHRC-funded study of Aboriginal inequality and the life course. His other recent work has examined the labour market experiences of older workers, as well as lone mothers and social assistance.

Amber Gazso is an Assistant Professor of Sociology at York University. Her research interests include: citizenship; gender and families; the feminization and racialization of poverty; social policy and the welfare state; and surveillance. Recent publications focus on the restructuring of social assistance in British Columbia, Alberta, and Saskatchewan and concurrent transformations in mothers' and fathers' social citizenship rights to income support. Her current research, funded by a Social Sciences and Humanities Research Council Standard Grant, explores how diverse Canadian families manage poverty intergenerationally through networks of formal and informal social support. 
Appendix: Slid Sample Characteristics and Percentage Receiving Social Assistance, Major Income Earners in Female Lone Parents Census Families, 2001.

\begin{tabular}{|c|c|c|}
\hline Female Lone Parents & $\%$ & $\% S A$ \\
\hline Separated & 383 & 24.2 \\
\hline Divorced or Widowed & 216 & 14.4 \\
\hline Single, never married & 167 & 38.9 \\
\hline \multicolumn{3}{|l|}{ Age At first marriage } \\
\hline Under 20 & 31 & 25.5 \\
\hline $20-25$ & 193 & 16.1 \\
\hline Over 25 & 110 & 12.7 \\
\hline \multicolumn{3}{|l|}{ Preschool children at home } \\
\hline None & 466 & 21.9 \\
\hline One & 110 & 33.6 \\
\hline Two or more & 22 & 40.9 \\
\hline \multicolumn{3}{|l|}{ Education } \\
\hline Less than High School & 94 & 47.9 \\
\hline High School & 220 & 27.7 \\
\hline Nonuniversity postsecondary & 284 & 14.8 \\
\hline \multicolumn{3}{|l|}{ University degree } \\
\hline \multicolumn{3}{|l|}{ Father's Education } \\
\hline Less than high school & 361 & 28.0 \\
\hline High school & 110 & 20.9 \\
\hline Degree or certificate & 52 & 9.6 \\
\hline Don't know & 58 & 29.3 \\
\hline Disability & 116 & 47.4 \\
\hline \multicolumn{3}{|l|}{ Province } \\
\hline Newfoundland/PEI/Nova Scotia & 57 & 19.3 \\
\hline New Brunswick & 101 & 37.6 \\
\hline Quebec & 135 & 25.2 \\
\hline Ontario & 31 & 25.8 \\
\hline Manitoba & 159 & 17.0 \\
\hline Saskatchewan & 32 & 31.3 \\
\hline Alberta & 38 & 23.7 \\
\hline British Columbia & 45 & 24.4 \\
\hline \multirow[t]{2}{*}{ Total } & 598 & 24.8 \\
\hline & Mean & s.d. \\
\hline Age & 39.17 & 8.76 \\
\hline Years work experience & 12.62 & 9.34 \\
\hline Age at $1^{\text {st }}$ Birth & 24.59 & 5.27 \\
\hline
\end{tabular}

